\title{
Concept and development of research-oriented education in the university context
}

\section{Oliver Vauderwange, Nicolas Javahiraly, Dan Curticapean}

Oliver Vauderwange, Nicolas Javahiraly, Dan Curticapean, "Concept and development of research-oriented education in the university context," Proc. SPIE 11143, Fifteenth Conference on Education and Training in Optics and Photonics: ETOP 2019, 1114306 (2 July 2019); doi: 10.1117/12.2524008 Photonics: ETOP 2019, 2019, Quebec City, Quebec, Canada 


\title{
Concept and development of research-oriented education in the university context
}

\author{
Oliver Vauderwange ${ }^{\text {ab }}$, Nicolas Javahiraly ${ }^{\mathrm{b}}$ Dan Curticapean $^{\mathrm{a}}$ \\ ${ }^{a}$ Offenburg University, Badstraße. 24, 77652 Offenburg, Germany \\ ${ }^{b}$ University of Strasbourg / ICube, Boulevard Sébastien Brant, BP 10413, F-67412, Illkirch, France
}

\begin{abstract}
The authors explain a developed concept for research-oriented education in optics and photonics. It is presented which goals are to be achieved, which strategies have been developed and how these can be implemented in a blended learning scenario. The goal of our education is the best possible qualification of the students on the basis of a strong scientific and research-oriented education, which also includes the acquisition of important interdisciplinary competences. All phases of a research process are to be mapped in the learning process and offer students an insight into current research topics in optics and photonics.
\end{abstract}

Keywords: research-oriented education, education and research, teaching and learning culture, optics and photonics.

\section{INTRODUCTION}

At the Offenburg University, students of the Faculty of Media and Information are offered a wide range of lectures with a broad spectrum of subjects from the fields of media informatics, media technology, media design and media economics in several courses of study. The aim is not to teach these areas separately, but to bring them together in interdisciplinary lectures, projects and applications. A suitable learning environment is crucial for the success of our teaching approach. A well-balanced mixture of theoretical lectures and practical sessions in the laboratories and in projects, combined with the advantages of modern digital media, is the base for our concept to convey all necessary topics and competences.

Teaching and study should be characterized by a student-oriented teaching and learning culture. Therefore it is very important to use modern educational methods and digital media to create an open and creative learning environment. From our point of view, this also includes the comprehensive integration of research projects into education. Good learning solutions are very complex and always require a high level of investment. It is therefore very necessary to develop a clear concept for research-oriented education that pursues a defined strategy. The aim of education in the Faculty of Media and Information at Offenburg University is the best possible qualification for students on the basis of a strong scientific and research-oriented education, which also includes the acquisition of important interdisciplinary skills.

\section{MISSION STATEMENT OF OFFENBURG UNIVERSITY}

Offenburg University is one of the leading universities for applied sciences in Germany with the independent profile technology, economy and media. The mission as an efficient educational institution is to enable its students to autonomously apply and further develop scientific knowledge and methods through qualified education. In accordance with the mission statement, all students should be assisted in their personal development. This applies in particular to independent scientific, artistic and creative thinking and working as well as social responsibility. The following extract from the mission statement for the mandate in education and research illustrates the significance of research-oriented education. [1]

"We strengthen the students' professional orientation, enable them to participate in research and development projects, convey well-founded methodological and technical knowledge and encourage their further professional and personal development through an appropriate learning environment. Media and electronically supported forms of teaching/learning support the learning process and improve the success of studies.

Efficient research is the basis for qualified and up-to-date education. The university is therefore vigorously continuing to strengthen its own research activities. This increasingly includes doctoral programmes in cooperation and/or alliances with other universities. In supporting lifelong learning, the university attaches great importance to the development of a broad range of advanced scientific training courses". [1]

* oliver.vauderwange@ hs-offenburg.de; phone +49 781 205-4608; fax +49 781 205-110; www.hs-offenburg.de 
In order to implement this mission statement for education, we provide our students with access to current research topics and the necessary resources already in the first semesters of the Bachelor's programs. This teaching strategy is intended to combine research and education throughout the Bachelor's and Master's programs.

\section{THEORETICAL PRINCIPLES}

In recent years, the efforts of German universities to combine teaching and learning ever more closely with research have become more visible. There is a great variety of approaches and formats, as well as names and titles such as "researchbased" or "research-oriented" or "research-based learning" or "teaching in research format". At the same time, with the multiplication of approaches of this type, the terms for them have become increasingly stretched and blurred. The same term is often used for different approaches, while on the other hand different terms are used for obviously identical programs. [2] [7] [8]

The literature offers some theoretical models for the systematic classification of the combination of research and teaching and learning. Healey and Jenkins developed the internationally most popular model for systematizing researchrelated teaching. Here, the different forms of implementation are subdivided with the help of two focal points, the content focus and the level of activity of the students. These two dimensions are now brought together, resulting in four different types of research reference in higher education teaching. In "research-led teaching", research results are communicated to students, while in "research-oriented teaching" the research process is explained to them. "Researchbased learning" refers to student research and "research-tutored learning" to the guided acquisition of research results. [3] [4] [9]

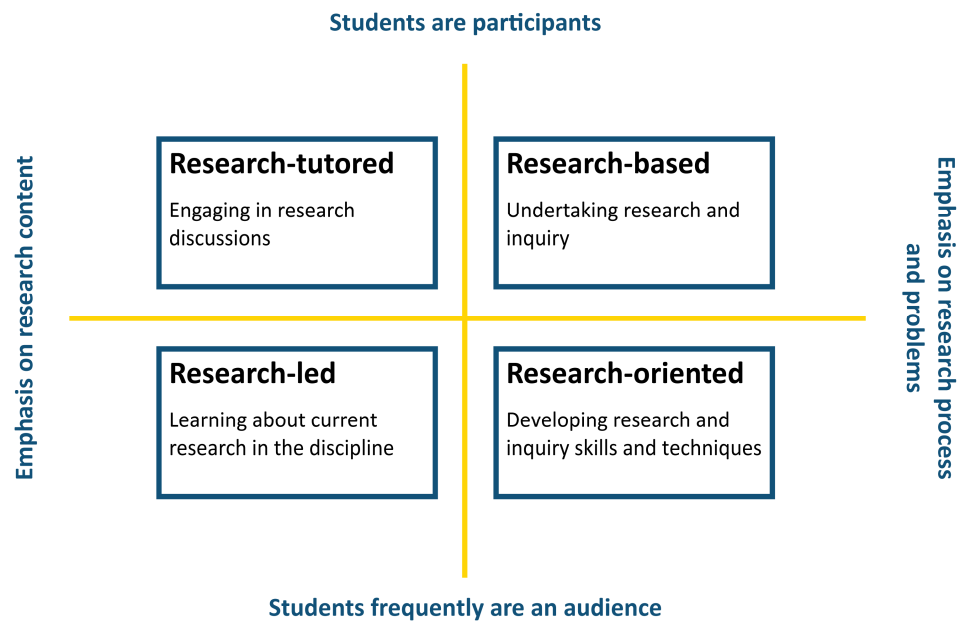

Figure 1. Research-Teaching Nexus by Healey und Jenkins (2009). [3] [4]

In 2014, Huber, in his elaboration for an understanding of concepts and differentiations in the field of research-related teaching and learning, chooses a similar, also strongly receptive systematization approach. First of all, it establishes the common references of the different approaches and describes their distinctive characteristics. It then subdivides researchrelated teaching into three types, highlighting the similarities with Healey's and Jenkins' Research-Teaching Nexus. In research-based learning (FBL), learning is based on research, whereby students are introduced to the current state of research as well as the basic problems and initial questions of this research. Research-oriented learning (FOL) leads to research and prepares students for autonomous research. Students learn how a research process can be designed. Special attention is given to the choice and implementation of research methods. Research-based learning (FL) means that students conduct active and autonomous research and in doing so go through the entire research process. It also proposes to use the term "research-related teaching and learning" as a neutral generic term for these different types. Thus, the common intention is expressed to combine research and study without determining the way, manner and level of connection from the start. [2] [7]

Rueß, Gess and Deicke use a less theoretical approach to systematizing research-related teaching on the basis of an analysis of curricula at various universities. Like the two approaches mentioned above, the starting point chosen is to differentiate between the focus of teaching and the level of activity of the students. A classification matrix is formed from the combination of these two comparative categories, each with three subcategories. The first category 
differentiates according to the content focus of the teaching, i.e. according to whether research results, research methods or the entire research process are the focus of attention. The second category asks about the degree of activity of the students and distinguishes whether the students learn receptively, whether they apply acquired knowledge or whether they themselves are active in research. Combining the two comparison categories creates a classification matrix that after empirical testing - differentiates between the various groups of research-related teaching. This classification matrix can be used empirically to differentiate between twelve groups of research-related teaching. It is general and applicable to all disciplines. [5] [6] [8]

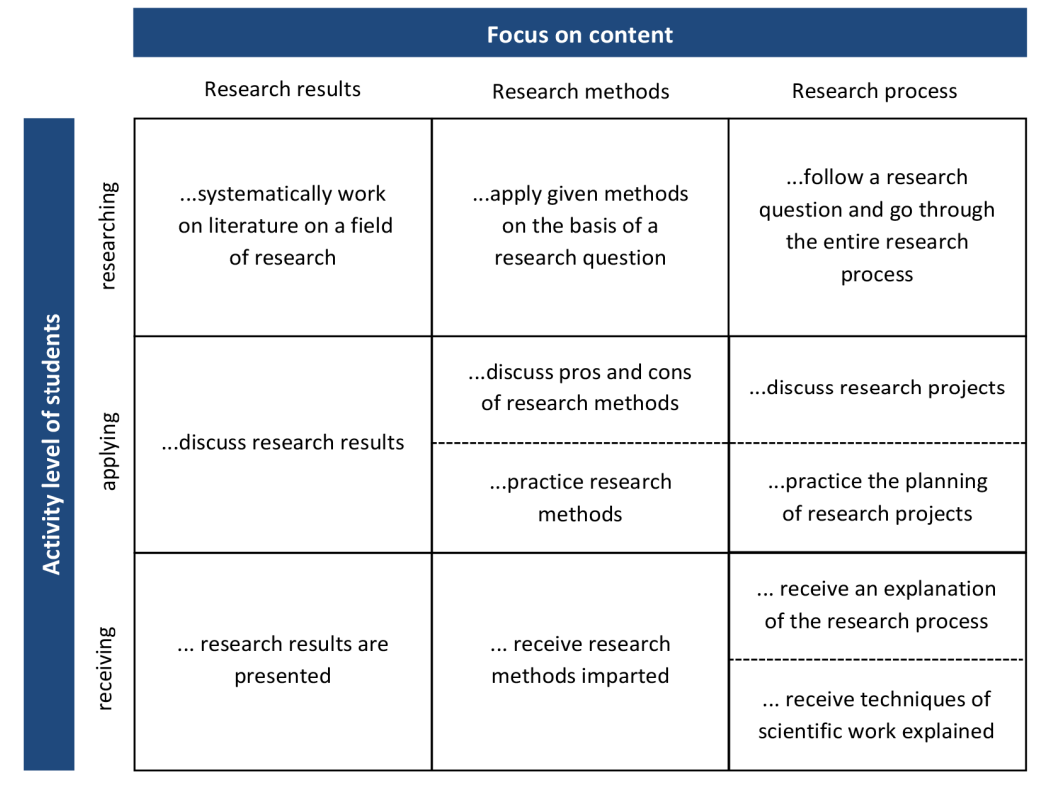

Figure 2. Matrix for the classification of research-related teaching according to Rueß, Gess \& Deike (2016). [5] [6] 8]

\section{CONCEPT FOR RESEARCH-ORIENTED TEACHING}

Offenburg University has established the format of research-oriented teaching as a central guiding principle of teaching in its mission statement. The research-oriented teaching strategy is to be incorporated into all courses of study and modules and increasingly practiced at the university. The term "research-oriented teaching" forms the framework for a variety of possibilities to combine the two main fields of activity of the university, research and teaching. [1]

\subsection{Objectives}

The research-oriented teaching at the Faculty Media and Information supports students in progressing from a comprehensive understanding of research topics, processes, methods and results to autonomous research as far as possible. For this purpose, the acquisition and deepening of professional knowledge as well as of interdisciplinary competences is made possible and specific research methodological skills are developed. Students should be able to autonomously identify future problems, derive appropriate questions from them and develop sustainable solutions for them with the help of scientific methods. [2] [3] [4] [8] [10]

The primary objective of our education is the best possible qualification of students on the basis of a strong scientific and research-oriented teaching, which also includes the acquisition of important interdisciplinary competences. By combining theoretical specialist knowledge with practical research work during our studies, we want to ensure that the students...

- develop a deeper understanding of science.

- develop a positive research attitude.

- develop methodological research skills.

- develop the ability to critically reflect on research activities and results.

- gain experience in collaborative scientific work with teaching researchers.

- be systematically prepared for possible future activities in research or development. 
The ability to understand scientific processes naturally also has its benefits in employments outside of research. Especially when assessing, evaluating and working with research results is part of the professional activity. [2] [3] [4] [8] [10]

\subsection{Teaching formats}

The term "research-oriented teaching" describes a wide variety of educational programs that combine the fields of research and teaching. The central idea here is to familiarize students with current research topics and processes in their subject in early semesters and providing them with the scientific methods with which they can face a problem and generate results. In our understanding, this means that we integrate typical research activities as essential elements of the learning process. We have therefore placed the general demand at the center of our concept that research should be made visible and tangible for our students. This implies that not only research results are presented, but that the entire process of achieving these results is made visible. The students are offered a concrete research context in the courses in order to gain an insight into the scientific research. [2] [3] [4] [8] [10]

Accompanied by various basic lectures, authentic, current and real issues are offered for autonomous study. This allows students to immerse themselves practically in subject-specific research. With scientific methods they work on problems and generate results. In addition, they collect theoretical knowledge, recognize the importance of knowledge for practice and can derive their own new insights through the application of this knowledge. They are accompanied by the teacher. The teacher provides suitable materials and specific theoretical input to support the work on the problem. Individual counselling is intended to encourage the students to look at the problem from different perspectives. The common exchange between teachers and learners as well as among students should be stimulated. Research-oriented teaching combines the theoretical and practical aspects of the scientific knowledge process and promotes the acquisition of specialist knowledge combined with the acquisition and development of interdisciplinary competences. [2] [3] [4] [8] [10]

On the base of the Research-Teaching Nexus, different teaching formats are offered to all teachers between lecturer and student activity as well as between the focal points research results and research processes/problems in order to realize different aspects of research-oriented teaching. The characteristics of the combination of teaching and research range from the basic lecture, in which students learn the basics of current research topics, processes and results, to active participation in the research discourse and autonomous work on (one's own) research projects (e.g. theses, project seminars) [3] [4] [9].

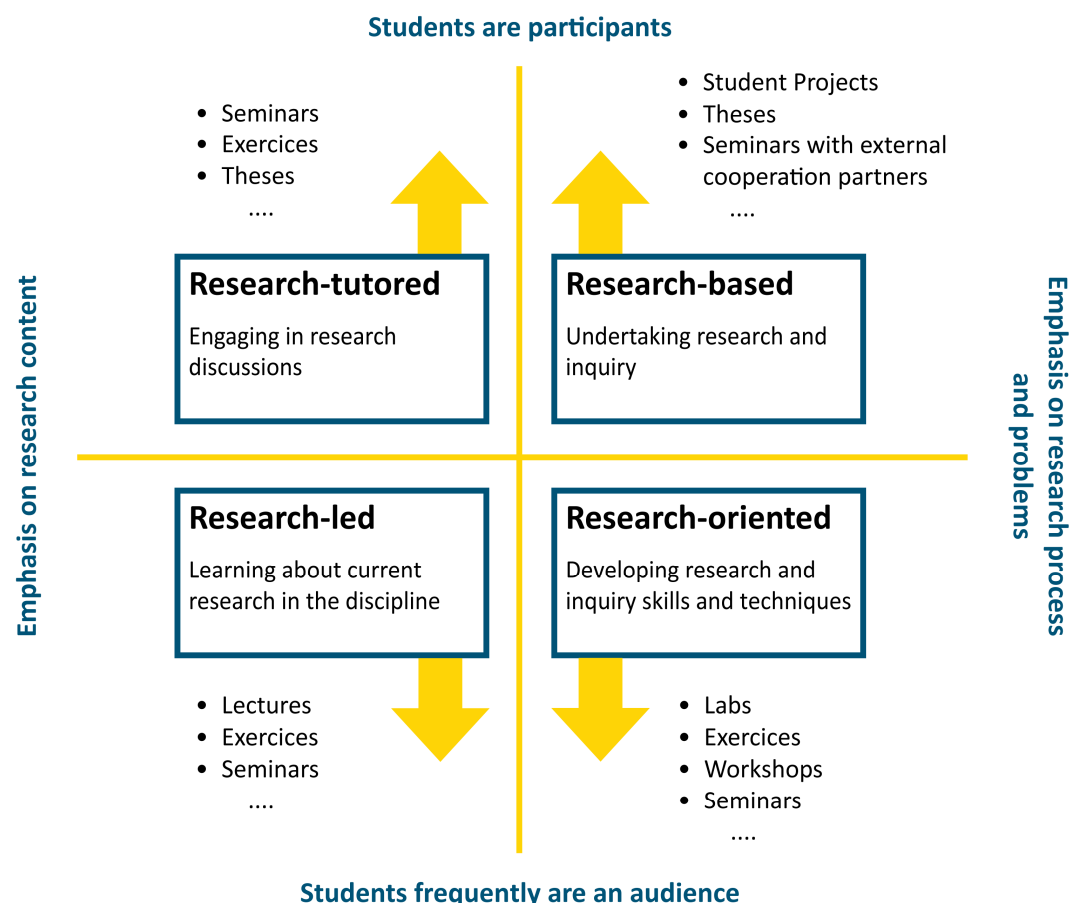

Figure 3. The planned teaching formats used in the concept, presented in the Research-Teaching Nexus. [3] [4] [9] 
At the Faculty of Media and Information, the following teaching formats are to be used to combine research and teaching under the framework of "research-oriented teaching":

- Lectures

- Exercises

- Courses on scientific work

- Labs

- Seminars

- Study projects

A closer look reveals that in the sense of the presented theory not only "research-oriented teaching" is offered, but that there are overlaps with all forms of research-related teaching. How the various aspects of research-oriented teaching can be used in different teaching formats is explained below. [3] [4] [8] [9]

Lectures offer the opportunity to convey the necessary basic knowledge. They are used to prepare students for autonomous research-oriented learning. Lectures offer many opportunities for this. Research results and research questions can be presented and critically reflected. Research methods used can be critically examined with their respective advantages and disadvantages and compared with each other. Lectures can also be used by lecturers to inform students on a personal level about their own work as scientists. [2] [8] [11] [12]

The aim of the exercise as a working format in study is to gain a deeper understanding of a subject through its own application, which, for example, was addressed in a lecture. Not all exercises can be designed to be research-oriented. In some exercises methods are presented and practiced which are used in research, e.g. statistical methods and data analysis. Here it is very important to describe the research context in which these methods can be used. These exercises have a preparatory character and precede independent research. It is important that students work on solutions as autonomously as possible. Working in small groups is very useful here. [2] [8] [11] [12]

Students should be introduced to the basics and the process of scientific work at an early stage of their studies. For this purpose, courses are offered in the form of seminars and workshops that are specifically focused on the topic of scientific work. These can be subject-specific or interdisciplinary. A research-orientation is given in particular if the students can contribute their own research projects in the form of project work, homework, theses or scientific papers to these events and thus apply the aspects of the activities to a concrete project. [2] [8] [11] [12]

Laboratory courses are an important part of teaching in engineering and natural sciences. Students are given the opportunity to apply methods in practice and to conduct research. However, the entire research cycle is not run through here. Various processes of the research cycle are pre-empted for organizational reasons. Nevertheless, students can experience different aspects of research as they are given the necessary freedom to make their own decisions. This should stimulate them to critically examine the task. [2] [8] [11] [12]

Seminars offer students the opportunity to systematically familiarize themselves with the entire research process. This enables students to deepen their knowledge of the main topics and the individual steps of the research process. Students should not only understand these, but should also be able to construct, apply and reflect on them themselves. It is important to clearly define all process steps and to give them clearly defined learning goals. [2] [8] [11] [12]

Study projects can be used through a research-oriented design to prepare students for research-based learning. They get a complex, open-solution problem. In order to solve this problem, they have to familiarize themselves with research methods. It is necessary to test teamwork and self-organization in the project and to practice the presentation of results. Depending on the tasks, a stronger development towards research-based learning is possible if the students are already involved in the selection of the research field, in the development of research questions and research design, and in the selection of research methods. The realization of the research, the evaluation and presentation of the results up to the reflection of the whole research process is completely in the hands of the students. [2] [8] [11] [12] 


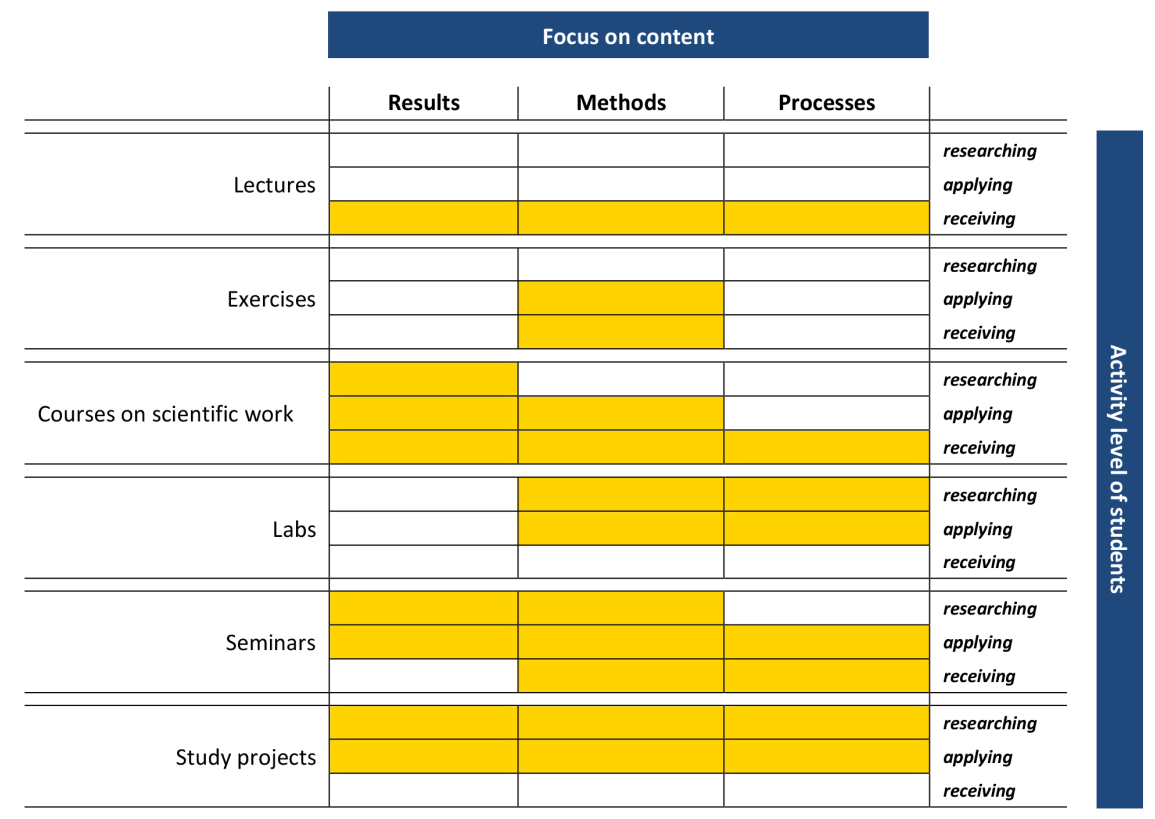

Figure 4. Categorization of teaching formats into the matrix for the classification of research-related teaching according to Rueß, Gess \& Deike (2016). Grey means that the level of activity and the focus of content are possible in our use of the teaching formats. [2] [5] [6] [8] [11]

\subsection{Digital tools}

The use of digital tools is essential for research and teaching today. These offer various functions in research-oriented teaching. The choice depends on the teaching format and the level of activity of the students. It is important here to plan the use of digital tools in advance in order to use them effectively in the overall research process. Many different digital tools are available in the relevant functional areas of research: collaboration, communication, investigation, documentation, visualization and presentation. These have a central role in the research process and accompany and support the entire research and teaching process. In certain contexts it is also possible and useful to combine them. [13]

\begin{tabular}{|c|c|c|c|c|c|c|c|}
\hline Digital tools & 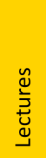 & 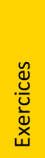 & 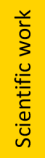 & $\frac{n}{\tilde{J}}$ & 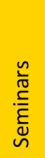 & 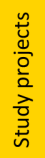 & Function in the concept \\
\hline Presentation tools & + & & & + & & + & Visualization, Presentation \\
\hline Educational videos & + & + & & + & + & & Investigation \\
\hline Discussion tools & + & + & + & & + & + & Collaboration, Communication \\
\hline Live voting & + & + & & & + & + & Collaboration, Communication \\
\hline Mindmapping tools & & & + & & + & + & Investigation, Communication \\
\hline Planning tools & & & + & & + & + & Collaboration, Communication, Documentation \\
\hline Management tools & & & + & + & & + & Investigation, Collection \\
\hline Open Access Portals & & & + & & & + & Investigation, Collection \\
\hline Data collection tools & & & + & & & + & Investigation, Collection, Visualization \\
\hline Virtual Meetings & & + & & + & & + & Collaboration, Communication \\
\hline
\end{tabular}

Figure 5. The table provides an overview of the teaching formats provided in the concept and the type of digital tools used and their functions. [13] 


\section{PLANNED IMPLEMENTATION OF THE CONCEPT}

In 2016 we presented in a paper the development of a blended learning concept for an engineering course in the field of color representation and display technologies. The engineering course "Media Technology: Color Representation and Display Devices" is an integral part of the second and third semesters of the studies. With a mixture of theoretical and practical lectures, we pursue the goal of providing students with a deeper understanding in the areas of digital color representation and display technologies. [14]

Blended learning describes a teaching and learning scenario that provides a didactically useful correlation between attendance and online periods. The aim is to make knowledge transfer and individual learning easier. Our blended learning scenario is a combination of different models that are used to better structure the broad concept of blended learning. It is based on a self-determined learning of the students. There is a fixed schedule for regular lectures, practical workshops and self-paced online learning. The concept is built on the e-learning software moodle, which is used at Offenburg University. Moodle is an internet-based open source software package for the development and implementation of e-learning courses under the GNU Public License. [14]

\subsection{Organization and teaching formats}

The engineering course "Media Technology: Color Representation and Digital Devices" is offered in semesters 2 and 3 in four integrated sections. The specific theoretical basics are conveyed in "Digital Media 2" and "Digital Media 3", the practical workshops are part of the media laboratory. A fixed schedule defines the attendance and online periods. In order to be able to implement the planned concept for research-oriented teaching, the organizational structure of the engineering course must be adapted and supplemented with further teaching forms. [14]

In preparation for the requirements of the course, students will be offered basic lectures on "Scientific Work" in the first semester. The actual organizational structure in the second and third semesters will be retained. In terms of researchoriented teaching, however, accompanying seminars and tutorials conducted by postgraduates will be added. [14]

\section{Blended Learning Course „Media Technology: Color Representation and Display Devices“}

Fixed Schedule over 2 Semesters

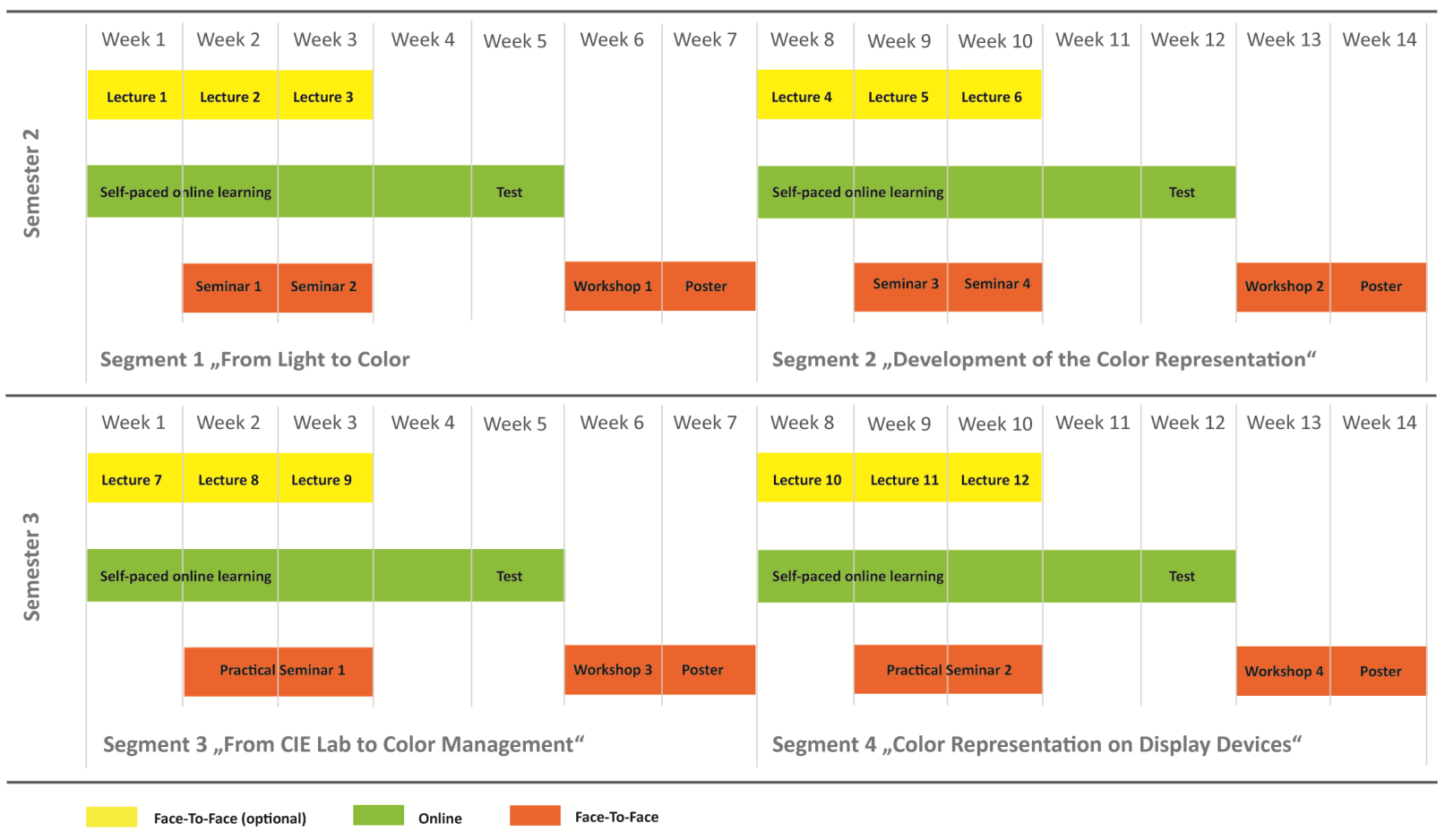

Figure 7. The extended schedule of the blended learning course „Media Technology: Color Representation and Display Devices". [14] 
Furthermore, three regular lectures are given for each segment. Also the online learning period with offered exercises and online support will be maintained. The online test must still be passed successfully in order to be admitted to the workshops in the media laboratory. As an extension of the course, two additional seminars will be offered in Segment 1 in the second semester. "Scientific Writing" offers a systematic review of the process. "Presentation technique and rhetoric" illustrates various aspects, techniques and technical tools. Two further seminars complete the course in segment 2. "Intuition and Creativity" gives insight into the current state of research and is to become experiencable by participation in the seminar. "Rational decision making" deals with behavior and decision theory. [14]

In the third semester, the offered seminars will be practice- and research-related. These seminars take place in the media laboratory on the basis of concrete tasks. In segment 3 the metrological calibration and the characterization of the color rendering of displays are critically considered in the context of the seminar. Segment 4 concludes with colorimetric experiments, which are part of a current research project within the framework of a $\mathrm{PhD}$ thesis. In addition, tutorials conducted by postgraduates on the required software applications are offered for the entire duration of the engineering course in order to provide students with the necessary skills. These tutorials are deliberately designed to meet the needs of the students and are therefore not included in the scheduled organizational structure. [14]

\subsection{Application of digital tools}

With moodle as an online platform, there is easy access to online learning materials with many interaction possibilities. E-learning is an excellent way to add digital media to established teaching scenarios. The online platform provides the entire content of the course. Literature, scientific papers and documents are made available. Animations, videos and podcasts for the visualization of content are integrated as well as preparatory exercises, tasks and tests to check the level of knowledge. Video tutorials and detailed technical instructions are available to prepare for the workshops in the media lab. Additional tools are used for presentation and visualization (MS PowerPoint, Adobe Illustrator, Prezi), investigation (Citavi, EvaSys, LimeSurvey, Wisemapping), collaboration and communication (Adobe Connect, Trello) and documentation (Trello). These are provided by the university or can be used as license-free online applications. [14]

\section{PERSPECTIVE}

We are constantly experiencing rapid development in the field of imaging and display technologies. The fast technological progress is a big challenge. Hardly any other field is changing so quickly. New technologies, devices and applications are changing the media world and the use of media. For this reason, it is very important for us that our teaching concept meets this progress. Continuous further development and adjustment to the constantly changing requirements in the field of media technology are necessary.

The aim of the blended learning concept is to make knowledge transfer and individual learning easier. The feedback from the students is very positive. Above all, they appreciate the virtual learning parts through the possibility to individually select the learning location and the learning time. Students are required to work independently and to develop individual solution strategies. Through the extension towards research-oriented teaching, we hope to achieve an even higher motivation to deepen knowledge and to work independently within the framework of the offered teaching. This is the best precondition to achieve the best possible qualification of our students on the basis of a strong scientific and research-oriented education.

\section{REFERENCES}

[1] ***, ,Leitbild der Hochschule Offenburg“, <http://www.hs-offenburg.de/die-hochschule/profil/leitbild> (27 April 2019).

[2] Huber, L., „Forschungsbasiertes, Forschungsorientiertes, Forschendes Lernen: Alles dasselbe?,“ Das Hochschulwesen, 62(1/2), pp 32-39 (2014).

[3] Healey, M., Jenkins, A., [Developing undergraduate research and inquiry], The Higher Education Academy, Heslington (2009).

[4] Healey, M., "Linking research and teaching: exploring disciplinary spaces and the role of inquiry-based learning," [Reshaping the University: New Relationships between Research, Scholarship and Teaching], McGraw-Hill Education, Berkshire, pp. 67-78 (2005). DOI: 10.1080/03098260500130387

[5] Rueß, R., Gess, C., Deicke, W., „Schärfung des Konzepts Forschendes Lernes im Kontext forschungsorientierter Lehre“, Potsdam, 02.09.2013. 
<https://bolognalab.hu-berlin.de/de/aktuelles/archiv/wiss_beitrag/schaerfung-des-konzeptes-forschendenlernen> (27 April 2019).

[6] Rueß, R., Gess, C., Deicke, W., „Forschendes Lernen und forschungsbezogene Lehre - Empirisch begründete Systematisierung des Forschungsbezugs hochschulischer Lehre,“ Zeitschrift für Hochschulentwicklung, Band 11(2), pp. 23-44 (2016). DOI: 10.3217/zfhe-11-02/02

[7] Huber, L., „Die weitere Entwicklung des Forschenden Lernens. Interessante Versuche - dringliche Aufgaben," [Forschendes Lernen als Profilmerkmal einer Universität: Beispiele aus der Universität Bremen], UVW Universitäts Verlag, Bielefeld, pp. 21-36 (2013).

[8] Sonntag, M., Rueß, J., Ebert, C., Friederici, K., Deike, W., „Forschendes Lernen im Seminar - Ein Leitfaden für Lehrende, “ Humbold-Uni zu Berlin, 2016, <https://www.researchgate.net/publication/308047837_Forschendes_Lernen_im_Seminar_Ein_Leitfaden_fur _Lehrende> (27 April 2019). DOI: 10.13140/RG.2.2.20857.67687

[9] Griffiths, R., "Knowledge production and the research-teaching nexus: the case of the built environment disciplines," Studies in Higher Education 29: 6, pp.709-726 (2004). DOI: 10.1080/0307507042000287212

[10] Reinmann, G., „Gestaltung akademischer Lehre: semantische Klärungen du theoretische Impulse zwischen Problem- und Forschungsorientierung," Zeitschrift für Hochschulentwicklung, Band 11(5), pp. 225-244 (2016).

[11] Kergel, D., Heidkamp-Kergel, B. „Didaktik des forschenden Lernens - handlungspragmatische Überlegungen, “ [Kritische Hochschullehre: Impulse für eine innovative Lehr- und Lernkultur], Springer, Wiesbaden, pp. 249-262 (2019). DOI: 10.1007/978-3-658-25740-8_13

[12] Reinmann, G., Mandl, H., „Unterrichten und Lernumgebungen gestalten,“ [Pädagogische Psychologie], 5. Überarbeitete Auflage, Beltz-Verlag, Weinheim, pp. 601-646 (2001).

[13] Igel, C. (ed.), [Bildungsräume: Proceedings der 25. Jahrestagung der Gesellschaft für Medien in der Wissenschaft, 5. Bis 8. September 2017, Chemnitz], Waxmann, Münster, New York (2017). DOI: 10.1365/s40702-014-01

[14] Vauderwange, O., Wozniak, P., Javahiraly, N., Curticapean, D., "A blended learning concept for an engineering course in the field of color representation and display technologies," Proc. SPIE 9946, Optics Education and Outreach IV, 99460Y (2016). DOI: 10.1117/12.2237612 